\title{
New guide on caring for indigenous patients
}

$\mathrm{T}$ he College of Family Physicians of Canada is inviting doctors to challenge their preconceptions about indigenous patients by learning more about how systemic and interpersonal racism jeopardizes health, and how to combat it.

The new guide, Health and Health Care Implication of Systemic Racism on Indigenous Peoples in Canada, was prepared by the college and the Indigenous Physicians Association of Canada in response to the Truth and Reconciliation Commission of Canada's Call to Action.

"Many [health care] practitioners don't know enough about what's going on in indigenous communities and families," Dr. Darlene Kitty, cochair of the college's Indigenous Health Working Group, said in an interview from Chiassibi, Quebec. "The lack of knowledge is one factor causing practitioners to make stereotypical assumptions and practices."

The guide opens by describing the 2008 death of Brian Sinclair as an example of how racism in the health care system "can be fatal." Sinclair, a 45-year-old indigenous man, was found dead in his wheelchair after waiting 34 hours to be seen for a treatable bladder

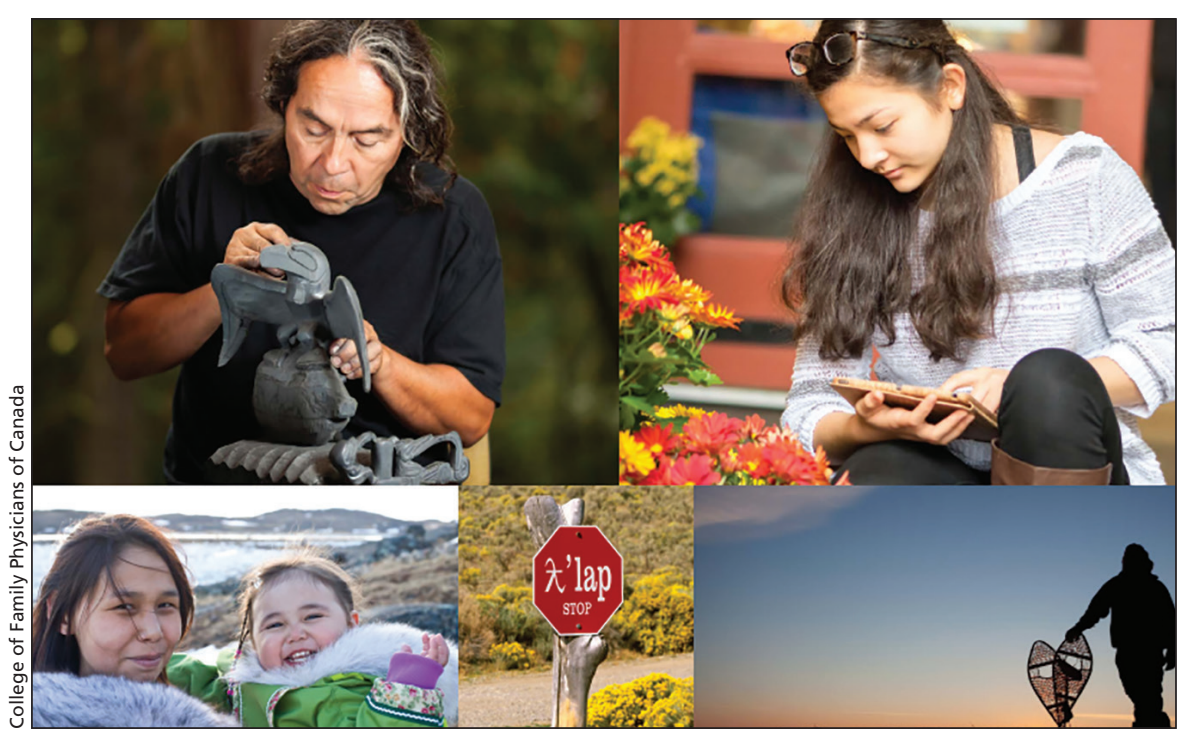

A new guide aims to help doctors overcome systemic racism.

as a residential school survivor, Kitty was able to help and treat him.

"What's important here is selfreflection," she said. "If physicians and other health care practitioners reflect on their attitudes, it could prompt a better understanding and better interactions among practitioners and patients."

The guide defines systemic and interpersonal racism, describes the way it affects the health of indigenous patients,

\section{"We need to look beyond the numbers and find out why they're bad."}

infection. Witnesses at a subsequent inquest testified that they assumed he was drunk and "sleeping it off" - an assumption that prevented them from checking on or treating him.

Sinclair's death is a widely known example of how health care practitioners' stereotypical views can affect care, and Kitty said she has seen similar examples. On one occasion, an intoxicated man who came into the emergency department seeking help for a medical problem was initially labelled a chronic drug-seeker. By supporting the man and acknowledging his history and provides resources and examples of how physicians can advocate for health equity and introduce "trauma-informed care" into their practices (care that acknowledges the effects of colonial policies and how they are linked to medical services for indigenous peoples).

"This document is a first step towards identifying the issues at hand, building interprofessional relationships and exploring resolutions to help ameliorate the delivery of health care to indigenous populations," Dr. Sarah Funnell, the working group's other cochair, told $C M A J$ in an email.
To build strong relationships, health care practitioners need to think about their perceptions of indigenous peoples and identify any potential biases or stereotypes that inform those perceptions.

"What's important to learn is not just the statistics around indigenous people's health - we know they are bad - but to look beyond the numbers and find out why they're bad," Kitty said.

The guide encourages family doctors to forge strong relationships by validating patients' ways of knowing and being; making them partners in health care decision-making; and allowing them to determine whether the care they receive is indeed culturally safe.

Doctors and other health practitioners are also encouraged to take cultural safety training courses, such as the Provincial Health Services Authority of British Columbia's online training. Laura Eggertson, Ottawa, Ont.

CMAJ 2016. DOI:10.1503/cmaj.109-5257

\section{More News online}

To read more CMAJ news articles, visit cmaj.ca/site/home/news.xhtml 